\title{
Corrigendum: Correlation Analysis Between Attentional Bias and Somatic Symptoms in Depressive Disorders
}

\author{
Yun Wang ${ }^{1,2}$, Yajun $\mathrm{He}^{3}$, Gaohua Wang ${ }^{2 *+}$, Jiangbo $\mathrm{Li}^{4 *+}$ and Haibing $\mathrm{Zhu}^{1 *}$ \\ ${ }^{1}$ Department of Psychiatry, Guangzhou Panyu Central Hospital, Guangzhou, China, ${ }^{2}$ Mental Health Centre, People's \\ Hospital of Wuhan University, Wuhan, China, ${ }^{3}$ Department of Pathology, Shenzhen Baoan District People's Hospital, \\ Shenzhen, China, ${ }^{4}$ Department of Clinical Psychology, Second People's Hospital of Wuhu, Wuhu, China
}

Keywords: depressive disorder, attentional bias, TORAWARE state, depression, somatic discomfort

\section{OPEN ACCESS}

Approved by:

Frontiers Editorial Office,

Frontiers Media SA, Switzerland

*Correspondence:

Gaohua Wang

wgh6402@163.com

Jiangbo Li

1015950973@qq.com

Haibing Zhu

zhb2@163.com

${ }^{+}$These authors have contributed equally to this work

Specialty section: This article was submitted to Mood and Anxiety Disorders, a section of the journal

Frontiers in Psychiatry

Received: 15 March 2020 Accepted: 24 March 2020 Published: 24 April 2020

Citation:

Wang Y, He Y, Wang G, Li J and Zhu H (2020) Corrigendum: Correlation

Analysis Between Attentional Bias and Somatic Symptoms in Depressive Disorders. Front. Psychiatry 11:293. doi: 10.3389/fpsyt.2020.00293

\section{A Corrigendum on}

Correlation Analysis Between Attentional Bias and Somatic Symptoms in Depressive Disorders by Wang Y, He Y, Wang G, Zhu $H$ and Li J-B (2019). Front. Psychiatry 10:903. doi: $10.3389 /$ fpsyt.2019.00903

In the original article, we neglected to include the following funding, "NSFC: Study on the role and mechanism of NLRP3 inflammatory cortisone/il-18/NF-B neuroinflammatory pathway in mediating the occurrence and outcome of depression, and 81871072 to GW."

Yajun $\mathrm{He}$ was not included as an author in the published article. In addition, Gaohua Wang should be included as a co-correspondence author in the published article. The Author Contributions statement has been corrected and appears below.

\section{AUTHOR CONTRIBUTIONS}

"The completion of the experiment and the writing of the article were mainly by YW. YH helped with data processing and analysis, and proofread the manuscript. GW helped strictly check the quality of the article and his project fund supported the successful conduct and completion of the research. LJ helped with corrections and revisions of this paper and also have given me a lot of advice on the shortcomings of the article. HZ provided partial fund support and academic guidance."

The authors apologize for these errors and state that this does not change the scientific conclusions of the article in any way. The original article has been updated.

Copyright (C) 2020 Wang, He, Wang, Li and Zhu. This is an open-access article distributed under the terms of the Creative Commons Attribution License (CC BY). The use, distribution or reproduction in other forums is permitted, provided the original author(s) and the copyright owner(s) are credited and that the original publication in this journal is cited, in accordance with accepted academic practice. No use, distribution or reproduction is permitted which does not comply with these terms. 